\title{
Mobile Communication through 5G Technology (Challenges and Requirements)
}

\author{
Naseer Hwaidi Alkhazaali1,2*, Raed Abduljabbar Aljiznawi1,2, Saba Qasim Jabbar ${ }^{1,3}$, \\ Dheyaa Jasim Kadhim ${ }^{3}$
}

${ }^{1}$ Signal School of Electronic Information and Communication Engineering, Huazhong University of Science and Technology, Wuhan, China

${ }^{2}$ Ministry of Communication, Iraqi Telecommunication and Post Company, Baghdad, Iraq

${ }^{3}$ Electrical Engineering Department, University of Baghdad, Baghdad, Iraq

Email: ^naserstar2007@yahoo.com

How to cite this paper: Alkhazaali, N.H., Aljiznawi, R.A., Jabbar, S.Q. and Kadhim, D.J. (2017) Mobile Communication through 5G Technology (Challenges and Requirements). Int. J. Communications, Network and System Sciences, 10, 202-207. https://doi.org/10.4236/ijcns.2017.105B020

Received: April 11, 2017

Accepted: May 23, 2017

Published: May 26, 2017

\begin{abstract}
Mobile communication through 5G technology is the key objective of this work. Existing research works in mobile communication through 5G technology in world submitted a great necessary development towards $5 \mathrm{G}$ technology in different work approaches including hardware and software. 4G technology includes several standards under a common umbrella, similar to previous generations of communication technologies. Actually $4 \mathrm{G}$ is good for now, however if look at it in five or ten years, $4 \mathrm{G}$ will obviously not be able to meet requirements for new applications coming up in the next few years. With 5G will increase the data rate, reduce the end-to-end latency, and improve coverage. These properties are particularly important for many applications related to IoT and $\mathrm{D} 2 \mathrm{D}$, which they are recognized as ones of the technology components of the evolving $5 \mathrm{G}$ architecture. The major contribution of this paper is the key provisions of mobile communication through $5 \mathrm{G}$ (Fifth Generation) technology of which is seen as consumer oriented. In 5G technology and mobile consumer has given top priority over others. 5G technology is to make use of mobile phones within very high bandwidth. The consumer never experienced the utmost valued technology as 5G.The 5G technologies comprise all types of sophisticated features which make 5G technology most governing technology in the vicinity of future.
\end{abstract}

\section{Keywords}

5G Technology, WLAN, GSM, LTE, PLMN

\section{Introduction}

Mobile and wireless networks have made significant improvement in the last few 
years. At the current time many mobile phones have also a WLAN adapter. One may expect that near soon many mobile phones will have Wax adapter too, besides their 3G, 2G, WLAN, Bluetooth etc. adapters. We are using IP for generations, 2.5G or 3G Public Land Mobile Networks (PLMN) on one side and WLAN on the other, developed study on their incorporation. With reference to the $4 \mathrm{G}$, its focal point is towards flawless integration of cellular networks such as GSM and 3G. The multiple consumers put plants as it should be for 4G, but private security mechanisms and private support for the operating system in the wireless test techniques remain. However, the application of a combination of different wireless networks (such as PLMN and WLAN) is in practice until the present time. Although, different wireless networks from only terminal are used absolutely, there is no combining of dissimilar wireless access technologies for an equal session (e.g., FTP download). The predictable Open Wireless Architecture (OWA) in is targeted to offer open baseband processing modules with open interface parameters. The OWA is related to MAC/PHY layers of future (4G) mobiles [1]. New error-control schemes can be downloaded from the Internet and augmentation is seen towards the customer terminals as a focus on the $5 \mathrm{G}$ mobile networks. The $5 \mathrm{G}$ terminals will have software defined radios and modulation scheme and the $5 \mathrm{G}$ mobile terminals will have access to diverse wireless technologies at the same time. And also 5G mobile terminal should be proficient to merge special flows from different technologies. The $5 \mathrm{G}$ terminal will make the final selection among diverse mobile access network providers for a particular service. The network will be reliable for managing user-mobility. The paper gives the concept of intelligent Internet [2] phone where the mobile can prefer the finest connections [3].

\section{Challenges in Migration from 4G to $5 G$}

Presently, 5G is not a term officially used for any particular specifications.3GPP standard release beyond 4G and LTE [4]. 5G Technology is a name used in a range of research papers and projects to point to the next most significant stage of mobile communication values beyond the $4 \mathrm{G}$ standards. The execution of standards under a 5G umbrella would likely be around the year of 2020. The following are the main constraints for migrating from $4 \mathrm{G}$ to $5 \mathrm{G}$.

\section{A. Multi mode user terminals}

This trouble caused by means of $4 \mathrm{G}$ can be solved by using software radio approach. There will be an essential to design a single user terminal that can operate in different wireless networks and overcome the design troubles such as boundaries on the size of the device, its cost and power utilization.

\section{B. Choice among various wireless systems}

Every wireless system has its distinctive characteristics and roles. The choice of most suitable technology for a specific service at a specific place and at precise time will be applied by making the choice according to the best possible fit of consumer QoS (Quality of Service) requirements.

\section{Security}


Mechanisms with adaptive, reconfigurable, and lightweight protection should be designed.

\section{Network infrastructure and QoS support}

Integrating the current non-IP and IP-based systems and providing QoS assurance for end-to-end services that engage different systems is a challenge.

\section{E. Charging and Billing}

It is hard to accumulate, handle and accumulate the Consumers' account information from many service providers. Consumers' billing is also a difficult task. Attacks on Application Level Software applications will offer new feature to the consumer, but will commence new bugs.

\section{F. Jamming and spoofing}

Criminals can make use of such techniques. Jamming occurs when a transmitter sending out signals at the same frequency shifts a GPS signal. Spoofing is fake GPS signals being sent out, in which case the GPS receiver considers that the signals arrives from a satellite and computes the wrong coordinates Data Encryption. If a GPS receiver will communicate with the main transmitter then the communication link between these two is not tough to break and consumer must use encrypted data [5].

\section{Key Terms of 5G Technology}

While considering a smooth migration for $5 \mathrm{G}$ it is apparent that it should be valid for all sorts of radio access technologies. So that it could make better revenue for current global operators as well as interoperability will become more feasible. To make $5 \mathrm{G}$ practical for all sorts of radio access technologies there should be some key terms of $5 \mathrm{G}$ technology as follows:

1. People called it REAL wireless world $5 \mathrm{G}$ is a completed wireless communication with almost no limitation; somehow Additional features such as Multimedia Newspapers, also to watch T.V programs with the clarity as to that of an HD T.V.

2. We can send Data much faster than that of the prior generations and $5 \mathrm{G}$ will bring almost perfect real world wireless or called "WWWW: World Wide Wireless Web

3. Real wireless world with no more limitation to access and zone issues and wearable devices with AI capabilities.

4. Internet protocol version 6 (IPv6), where a visiting care-of mobile IP address is assigned according to location and the connected network [6].

5. One unified global standard and persistent networks providing ubiquitous computing: The user can simultaneously be connected to several wireless access technologies and seamlessly move between them. These access technologies can be a $2.5 \mathrm{G}, 3 \mathrm{G}, 4 \mathrm{G}$ or $5 \mathrm{G}$ mobile networks, Wi-Fi, PAN or any other future access technology [9]. In 5G, the concept may be further developed into multiple concurrent data transfer paths [7].

6. Cognitive radio technology, also known as smart-radio: This dynamic radio resource management is achieved in a distributed fashion, and relies on 
software defined radio allowing different radio technologies to share the same spectrum efficiently by adaptively finding unused spectrum and adapting the transmission scheme to the necessities of the technologies currently sharing the spectrum. See also the IEEE 802.22 standard for Wireless Regional Area Networks [8].

7. High altitude stratospheric platform station (HAPS) systems.

\section{5G Technology Requirements}

As a result of this blending of requirements, many of the industry initiatives that have progressed with work on $5 \mathrm{G}$ identify a set of eight requirements:

1. 1-10 Gbps connections to end points in the field (i.e. not theoretical maximum)

2. 1 millisecond end-to-end round trip delay (latency)

3. $1000 \times$ bandwidth per unit area

4. 10-100 $\times$ number of connected devices

5. (Perception of) $99.999 \%$ availability

6. (Perception of) $100 \%$ coverage

7. $90 \%$ reduction in network energy usage

8. Up to ten year battery life for low power, machine-type devices

Because these requirements are specified from different perspectives, they do not make an entirely coherent list-it is difficult to conceive of a new technology that could meet all of these conditions simultaneously.

\section{5G Technology Features}

5G technology is going to be a new mobile revolution in mobile market. Through 5G technology now you can use worldwide cellular phones. With the coming out of cell phone alike to PDA now your whole office in your finger tips or in your phone [9]. 5G technology has extraordinary data capabilities and has ability to tie together unrestricted call volumes and infinite data broadcast within latest mobile operating system. $5 \mathrm{G}$ technology has a bright future because it can handle best technologies and offer priceless handset to their customers. May be in coming days $5 \mathrm{G}$ technology takes over the world market. 5G Technologies have an extraordinary capability to support Software and Consultancy. The Router and switch technology used in 5G network providing high connectivity [10]. The 5G technology distributes internet access to nodes within the building and can be deployed with union of wired or wireless network connections [11]. The current trend of $5 \mathrm{G}$ technology has a glowing future. The following points are summerized the main feature of $5 \mathrm{G}$ technology:

- 5G technology will offer high resolution for crazy cell phone user and bidirectional large bandwidth shaping.

- The advanced billing interfaces of 5G technology will makes it more attractive and effective.

- 5G technology will provide subscriber supervision tools for fast action.

- The high quality services of 5G technology based on Policy to avoid error. 
- 5G technology will provide large broadcasting of data in Gigabit which supporting almost 65,000 connections.

- 5G technology will offer transporter class gateway with unparalleled consistency.

- The traffic statistics by $5 \mathrm{G}$ technology will make it more accurate.

- Through remote management offered by 5G technology a user can get better and fast solution.

- The remote diagnostics will be a great feature of $5 \mathrm{G}$ technology.

- The 5G technology will provide up to $25 \mathrm{Mbps}$ connectivity speed.

- The $5 \mathrm{G}$ technology will support virtual private network.

- The new 5G technology will take all delivery service out of business prospect

- The uploading and downloading speed of 5G technology will touch the peak.

- The 5G technology network will offer enhanced and available connectivity just about the world.

$5 \mathrm{G}$ technology is about to begin because $5 \mathrm{G}$ technology going to give tough completion to normal computer and laptops whose marketplace value will be effected. There are lots of improvements from $1 \mathrm{G}, 2 \mathrm{G}, 3 \mathrm{G}$, and $4 \mathrm{G}$ to $5 \mathrm{G}$ in the world of telecommunications. The new coming $4 \mathrm{G}$ technology is available in the market in affordable rates, high peak future and much reliability than its preceding technologies [12].

\section{Conclusion and Future Scopes}

In this paper we have surveyed mobile communications through $5 \mathrm{G}$ technology. $5 \mathrm{G}$ technology has been designed as a platform open to different layers, from the physical layer up to the application. A new revolution of $5 \mathrm{G}$ technology is about to begin because the technology 5G going to give the completion of difficult computer and laptops that will be affected the normal market value. At present, the current work is in units that must offer the best operating system and at the lowest cost to serve the specified using one or more than one wireless technology at the same time from the mobile phone 5G. There are a lot of improvements from 1G, 2G, 3G, 4G 5 G well in the world of mobile communications. And mobile phones $5 \mathrm{G}$ access to different wireless technologies in the identical time and the station should be able to integrate different streams of different technologies. Available in the market at cheap prices, expectations of high peak and a lot of reliability of the technologies have already new technology coming 5G. We can watch HD TV channel in our mobile phones without any inconvenience. 5G network technology will release a novel era in mobile communication.5G technology provides high accuracy consumer mobile phone passionate. 5G and mobile phones have a Tablet PC. Many of the compact mobile technologies evolve.

\section{References}

[1] Bria, A., Gessler, F., Queseth, O., Stridth, R., Unbehaun, M., Wu, J. and Zendler, J. (2001) 4-the Generation Wireless Infrastructures: Scenarios and Research Challenges. IEEE Personal Communications, 8, December. 
https://doi.org/10.1109/98.972165

[2] Janevski, T. (2005) A System for PLMN-WLAN Internetworking. Journal of Communications and Networks (JCN), 7, 192-206.

https://doi.org/10.1109/JCN.2005.6387866

[3] McNair, J. and Zhu, F. (2004) Vertical Handoffs in Fourth-Generation Multi-network Environments. IEEE Wireless Communications, June. https://doi.org/10.1109/MWC.2004.1308935

[4] Janevski, T. (2003) Traffic Analysis and Design of Wireless IP Networks. Artech House Inc., Boston.

[5] Hui, S.Y. and Yeung, K.H. (2003) Challenges in the Migration to 4G Mobile Systems. IEEE Communications Magazine, December.

[6] Lu, W.W. (2008) An Open Baseband Processing Architecture for Future Mobile Terminals Design. IEEE Wireless Communications, April. https://doi.org/10.1109/MWC.2008.4492984

[7] Govil, J. 5G: Functionalities Development and an Analysis of Mobile Wireless Grid. First International Conference on Emerging Trends in Engineering and Technology.

[8] Hata, M. (1999) Fourth Generation Mobile Communication Systems beyond IMT-2000 Communications. Proc 5th Asia Pacific Conf. Commun. 4th Optoelect. Commun. Conf., 1, 765-767. https://doi.org/10.1109/apcc.1999.825015

[9] Bhalla, M. and Bhalla, A. (2010) Generations of Mobile Wireless Technology: A Survey. International Journal of Computer Applications, 5, August.

[10] Janevski, T. (2009) 5G Mobile Phone Concept. CCNC Conference in Las Vegas. https://doi.org/10.1109/ccnc.2009.4784727

[11] Tudzarov, A. and Janevski, T. (2011) Design of 5G Mobile Architecture. International Journal of Communication Networks and Information Security, 3, August.

[12] Singh, S. and Singh, P. (2012) Key Concepts and Network Architecture for 5G Mobile Technology. International Journal of Scientific Research Engineering \& Technology, 1, 165-170.

Submit or recommend next manuscript to SCIRP and we will provide best service for you:

Accepting pre-submission inquiries through Email, Facebook, LinkedIn, Twitter, etc. A wide selection of journals (inclusive of 9 subjects, more than 200 journals)

Providing 24-hour high-quality service

User-friendly online submission system

Fair and swift peer-review system

Efficient typesetting and proofreading procedure

Display of the result of downloads and visits, as well as the number of cited articles

Maximum dissemination of your research work

Submit your manuscript at: http://papersubmission.scirp.org/

Or contactijcns@scirp.org 